\title{
A Study on Crown and Bridge Resin using PNC-EMA Monomer*
}

\author{
by \\ Misaki ANZAI, Ken HOYA, Fumito TORIYAMA, Kohzo IDE, \\ Hisaji KIKUCHI, Hideharu HIROSE, Masashi YUDA** \\ and Masayoshi OHASHI
}

(Received 27 May 1986)

Key words: crown and bridge resin, PNC-EMA monomer

\section{Summary}

The present study investigated the development of crown and bridge resin using a new PNC-EMA monomer. MMA monomer has long been used for crown and bridge resins, but the polymer prepared with MMA monomer has certain demerits such as low mechanical strength and abrasion resistance. The authors prepared a polymer by mixing 3PNC-EMA monomer having a $\mathbf{P}=\mathbf{N}$ bond in its skeleton, previously synthesized by ANZAI et al, with a monomer currently available on the market, in proportions of $14 \sim 70 \%$ (wt), using PMMA as the polymer. Both the compressive strength and hardness increased in accordance with increased amounts of the mixed 3PNC-EMA monomer, but water sorption reached 1.86 $\mathrm{mg} / \mathrm{cm}^{2}$ when the mixed amount of 3PNC-EMA was $28 \%$. The degree of abrasion decreased in accordance with the increase in the mixed amount of 3PNC-EMA, showing a value $1 / 3$ that of PMMA, when mixed in a proportion of $70 \%$.

\section{Introduction}

Monomer-polymer polymerization resin with MMA and PMMA used as the main components has hitherto been employed as crown and bridge resin. Recently, thanks to the application of various kinds of polyfunctional methacrylate, its physical properties have not only been remarkably improved, but also, because of its simple polymerization manipulation and preferable aesthetics, it has become more widely used ${ }^{[1]}$. However, this resin has low mechanical strength, and especially low abrasion resistance, and for these reasons, its clinical reputation has not always been satisfactory. In order to improve these demerits, various methods have been studied such as those using cross-linking monomers ${ }^{[2-4]}$ or PMMA powder mixed with inorganic or organic fillers ${ }^{[5-7]}$, but no success has ever been reported in strengthening the matrix of polymers ${ }^{[8,9]}$.

安斉 碕, 保谷 賢, 鳥山史人, 井出隆三, 菊地久二, 廣瀬英晴, 晹目雅上**, 大憍正敬：Department of Dental Materials, Nihon University School of Dentistry and Dental Technician Training School, Nihon University School of Dentistry**.

* Studies on the Improvement of the Physical Properties of Dental Resin (4). 
In an attempt to resolve these problems, the authors have examined various kinds of monomers, and in the present series of studies aimed at improving the physical properties of resin, especially mechanical strength and abrasion resistance, they selected and examined hexa (methacryloxyethylenedioxy) cyclotriphosphazene (3PNC-EMA) which had previously been synthesized by ANZAI et al. ${ }^{[10-13]}$ as a monomer to be used for strengthening the matrix of the polymer.

3PNC-EMA $\left[\mathrm{P}_{3} \mathrm{~N}_{3}\left(\mathrm{OCH}_{2} \mathrm{CH}_{2} \mathrm{OOC}\left(\mathrm{CH}_{3}\right) \mathrm{C}=\mathrm{CH}_{2}\right)_{6}\right]$ is a monomer which has a hetero bond, $-\stackrel{+}{\mathbf{P}}=\mathrm{N}$ - in its skeleton, and its bulk polymer, compared with conventional Bis-GMA polymers, has both large compressive strength and hardness, and a small degree of polymerization shrinkage with a low thermal expansion coefficient. Thus, by using this as the monomer component of crown and bridge resin, improved physical properties unobtainable with conventional monomers can be expected.

As 3PNC-EMA monomer, when used alone, cannot make PMMA swell or dissolve, the authors prepared a monomer for the resin used in the present study by mixing it with several which are available on the market, i.e., MMA, BPDMA [2, 2-Bis (4-methacryloxy) phenyl propane] and TEDMA (triethyleneglycol dimethacrylate), and examined the relationship between the mixed amount of 3PNCEMA monomer and the resulting physical properties to determine the optimum monomer composition for a crown and bridge resin.

\section{Materials and Methods}

1. Materials

Powder: $10(\mathrm{wt} \%)$ of $88 \mu \mathrm{m}$ and $90(\mathrm{wt} \%)$ of $74 \mu \mathrm{m}$ PMMA powder (Negami Co.) were mixed, to which $0.3 \%$ of BPO was added.

Liquid: Monomer composition is shown in Table 1.

2. Methods

1) The powder-liquid ratio $(\mathrm{L} / \mathrm{P})$ showing preferable fluidity was 0.75 .

2) Mold dimensions for specimens were as follows:

(1) $4 ø \times 8 \mathrm{~mm}$ for compressive strength test

(2) $30 \times 3 \times 3 \mathrm{~mm}$ for transverse strength test, distance between fulcrums, $25 \mathrm{~mm}$

(3) $10 \varnothing \times 5 \mathrm{~mm}$ for hardness test

(4) $18 ø \times 2 \mathrm{~mm}$ for water sorption test and

(5) $12 ø \times 10 \mathrm{~mm}$ for abrasion resistance test

Table 1 Monomer composition

\begin{tabular}{lcccc}
\hline & \multicolumn{4}{c}{ Monomer } \\
\cline { 2 - 5 } No. & 3PNC-EMA & MMA & BPDMA & TEDMA \\
\hline 1 & - & 40 & 20 & 40 \\
2 & 14 & 32 & 16 & 38 \\
3 & 28 & 24 & 12 & 36 \\
4 & 42 & 16 & 8 & 34 \\
5 & 56 & 8 & 4 & 32 \\
6 & 70 & - & - & 30 \\
\hline
\end{tabular}


3) Specimens for experiments were prepared as follows:

A prescribed amount of the composition shown in Table 1 was put into a glass vessel together with a fixed amount of polymer, and after removing air bubbles with a vibrator, the mixture was poured into the respective molds prepared in 2), immediately placed in a furnace (Sankin Co.) at $140 \pm 2^{\circ} \mathrm{C}$ and polymerized for 15 minutes $^{[7]}$ at $4 \mathrm{~kg} / \mathrm{cm}^{2}$ pressure. After polymerization, specimens were finished and reduced to the prescribed dimensions at room temperature with JIS \#800 carborundum paper.

4) Compressive strength and transverse strength were measured with a universal tester (Minebea Co. TCM 5000A), with a crosshead speed of $1 \mathrm{~mm} / \mathrm{min}$.

5) Hardness was measured with a Rockwell hardness tester (Akashi Co.), with a 1/8-inch steel ball, a 30-kg load and a 39-second loading time. The meterindicated values were read 30 seconds after removal of the load.

For experiments 4) and 5), dry specimens and those immersed in water at $37^{\circ} \mathrm{C}$ were used.

6) Water sorption was measured as follows:

Specimens were weighed and placed in a desiccator (containing silica gel) until they reached a fixed weight, and were then immersed in pure water at $37^{\circ} \mathrm{C}$ for 7 days. After being taken out and wiped with tissue paper to remove attached water, they were weighed again in order to calculate the amount of weight increase, and the difference between the new weight and the original weight was expressed in $\mathrm{mg} / \mathrm{cm}^{2}$.

7) Abrasion resistance ${ }^{[14]}$ was measured using a nylon disk brush $(25 \mathrm{~cm}$ in diameter). Abrasion conditions were as follows: Specimens saturated with water were loaded with a $100-\mathrm{g}$ weight, onto which $50 \%$ tooth paste dissolved in pure water was dropped and abrasion was conducted for 24 hours at $60 \mathrm{rpm}$. Abrasion ratio was determined by measuring the abrasion weight and specific gravity of specimens in order to calculate abrasion volume. At the same time, the abrasion ratio of the commercially available PMMA was also measured by the same method and used to represent the comparative abrasion ratio of tested specimens, regarding the ratio of PMMA as 1 .

\section{Results and Discussion}

1. Compressive strength and elastic modulus

Figure 1 shows the proportional limit of compressive strength corresponding to the change of monomer composition, and Fig. 2 shows the elastic modulus of specimens when compressed.

The wet specimen No. 1 showed a compressive strength approximately $100 \mathrm{~kg} / \mathrm{cm}^{2}$ less than that of the dry one, but in accordance with the change in composition from No. 2 to No. 6, both the wet and dry compressive strengths showed a tendency to increase. This proved that the compressive strength increases in accordance with the increase of the mixed amount of 3PNCEMA. However, when No. 6 was compared with No. 1, the compressive strength of the wet sample showed a tendency to be more decreased.

On the other hand, the elastic modulus showed a tendency to increase 


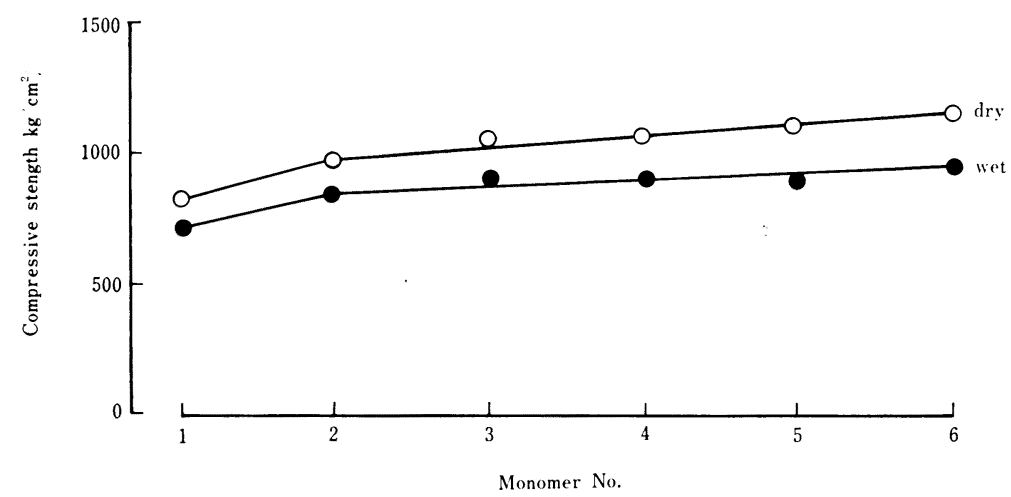

Fig. 1 Monomer composition and compressive strength

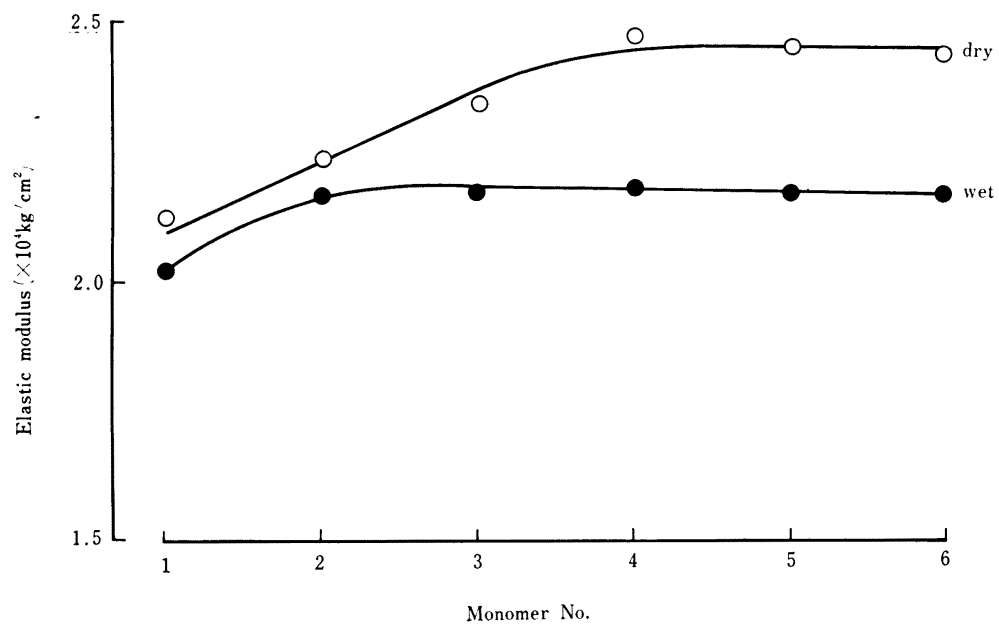

Fig. 2 Monomer composition and elastic modulus

in accordance with the increase in the mixed amount of 3PNC-EMA, the dry sample of specimen No. 4 showing an especially large value of $2.49 \times 10^{4}$ $\mathrm{kg} / \mathrm{cm}^{2}$ whereas the wet sample showed that although the elastic modulus increased up to No. 2, it showed no change thereafter, even when the mixed amount of 3PNC-EMA was increased from No. 3 to No. 6.

2. Transverse strength

Figure 3 shows transverse strength. In the case of dry specimens, transverse strength increased in accordance with the change from No. 1 to No. 4, but contrarily, it decreased for Nos. 5 and 6. Again, the wet specimen of sample No. 2 showed the maximum value, $474 \mathrm{~kg} / \mathrm{cm}^{2}$.

\section{Hardness}

Figure 4 shows hardness. In the case of dry specimens, hardness increased from $\mathrm{Hr} 46$ to 66 in accordance with the change in composition 


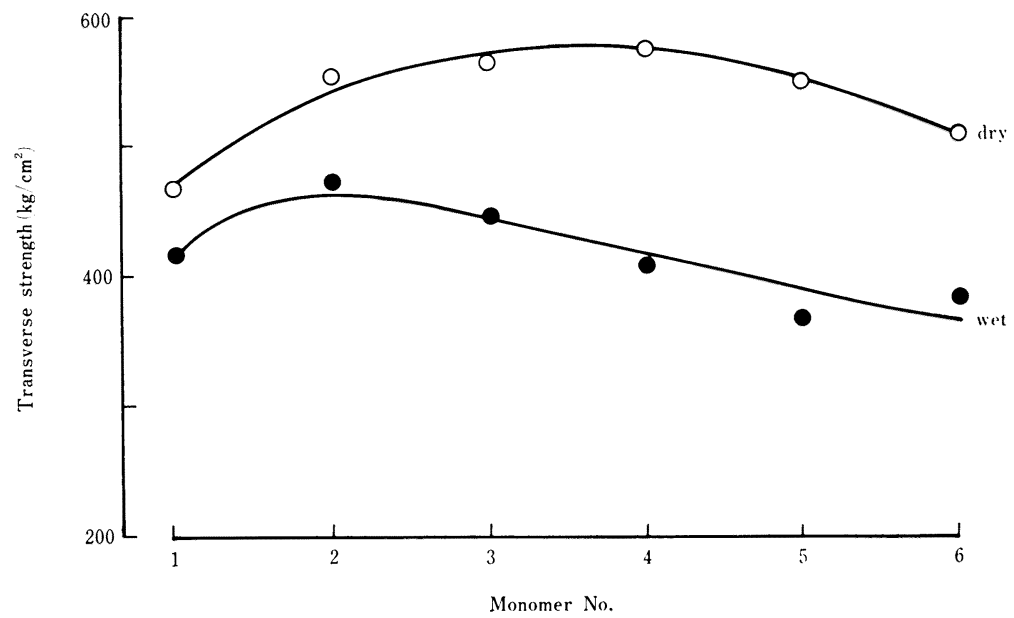

Fig. 3 Monomer composition and transverse strength

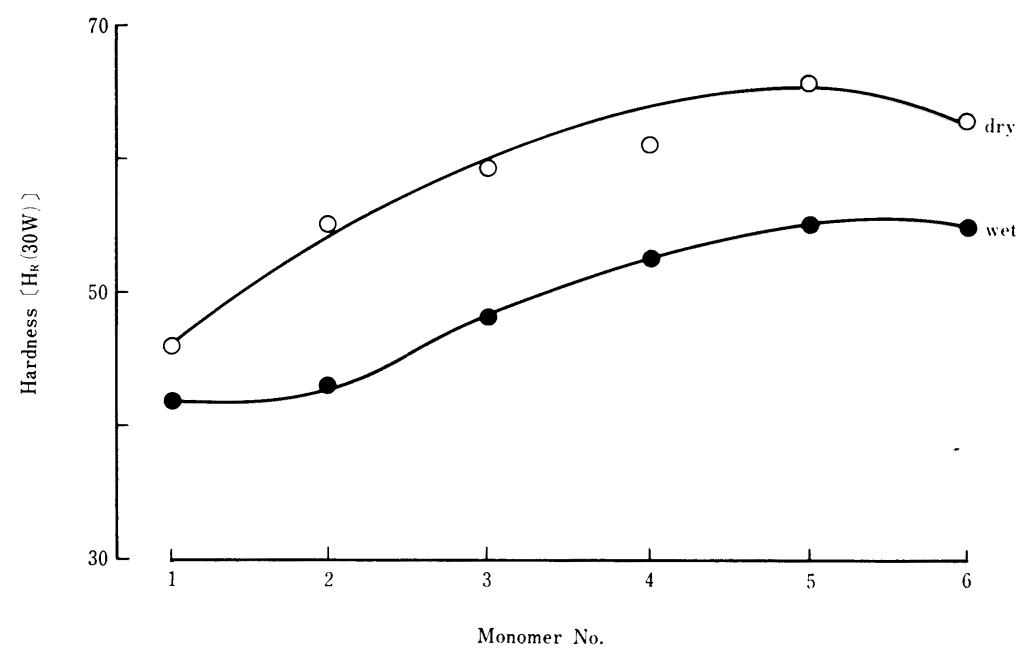

Fig. 4 Monomer composition and hardness

from No. 1 to No. 5, showing the remarkable effect of 3PNC-EMA on hardness. However, at No. 6 it slightly decreased. Again, in the case of wet specimens, although hardness increased in accordance with the increase in the mixed amount of 3PNC-EMA, the $\mathrm{HR}$ for any composition was smaller than that of the dry one by a value of about 10 .

4. Water sorption

Figure 5 shows water sorption. Water sorption increased in accordance with the change in composition from No. 1 to No. 3, showing $1.86 \mathrm{mg} / \mathrm{cm}^{2}$, 


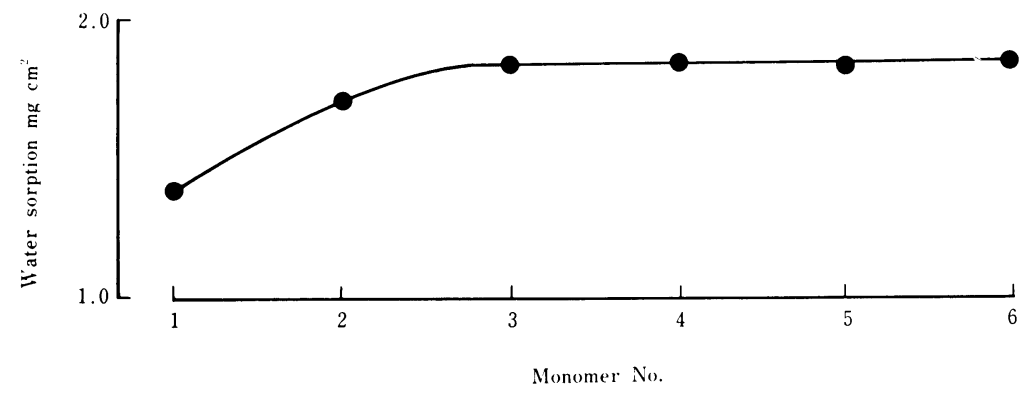

Fig. 5 Monomer composition and water sorption

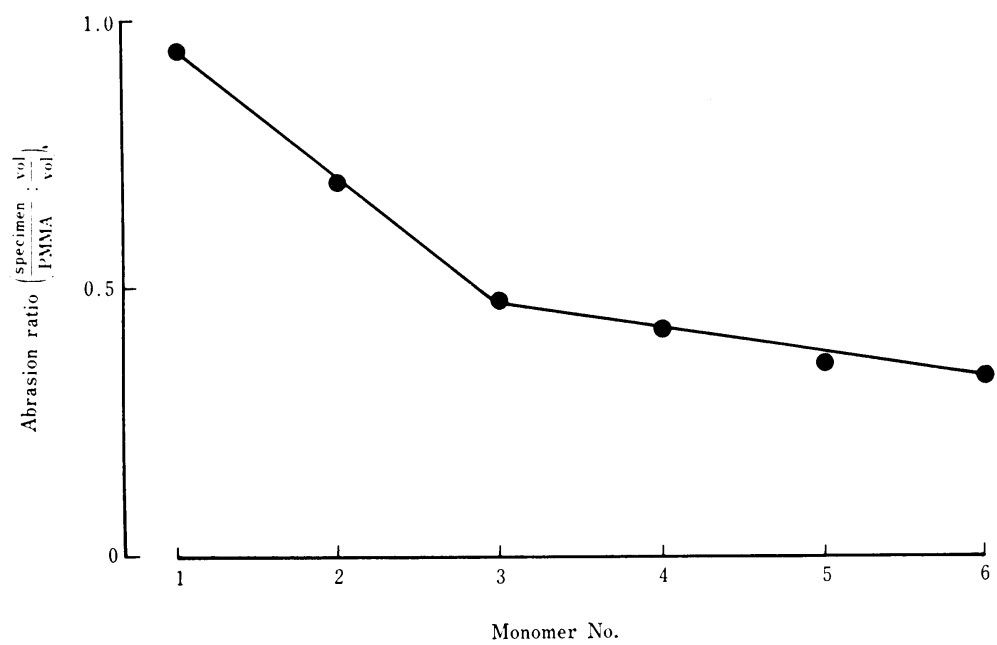

Fig. 6 Monomer composition and abrasion ratio

but it was shown that no further outstanding change occurred, even when the mixed amount of 3PNC-EMA was increased.

5. Abrasion resistance

Figure 6 shows abrasion ratio. The abrasion ratio decreasing in accordance with the change in composition from No. 1 to No. 3, showed a value of 0.49 at No. 3, that is, the abrasion resistance was approximately twice as large as that of PMMA. Furthermore, the curve gradually decreased, as the mixed amount of 3PNC-EMA increased, up to a value of 0.34 , until at sample No. 6, the abrasion resistance became approximately 3 times as large as that of PMMA.

It was therefore shown that in the case of dry specimens, in accordance with the increase in the amount of 3PNC-EMA mixed with commercially available monomers, the compressive strength, elastic modulus, transverse strength and hardness showed a tendency to increase. On the other hand, 
in the case of wet specimens, the compressive strength, elastic modulus and transverse strength showed an abrupt increase when the mixed amount of 3PNC-EMA was increased from $0 \%$ to $14 \%$, after which no remarkable change with regard to the compressive strength and elastic modulus, occurred even when the mixed amount of 3PNC-EMA was increased, whereas the transverse strength showed a tendency to decrease.

It is thus obvious even from the relationship between monomer composition and water sorption that the strength of wet specimens is decreased more than that of dry ones. This is presumably due to 3PNC-EMA itself.

As 3PNC-EMA has an oxy-bonded structure between the $\mathrm{P}$ of the $\mathrm{P}_{3} \mathrm{~N}_{3}$ ring $^{[10-13]}$ and the $\mathrm{O}$ of EMA $\left[\mathrm{P}_{3} \mathrm{~N}_{3}\left(\mathrm{OCH}_{2} \mathrm{CH}_{2} \mathrm{OOC}\left(\mathrm{CH}_{3}\right) \mathrm{C}=\mathrm{CH}_{2}\right)_{6}\right]$, it is considered that the increase in water sorption due to the ester bond of EMA causes a deterioration in the mechanical properties. On the other hand, 3PNC-EMA, with a molecular weight of 909.8 , is a comparatively highviscosity monomer $\left(23^{\circ} \mathrm{C}, 20 \text { poise }\right)^{[10]}$. Therefore, it is considered that swelling of a polymer in this monomer would be difficult. In other words, when a large amount of 3PNC-EMA is mixed with commercially available monomers, the degree of polymer swelling decreases, and the bond between the core part of the polymer and the monomer-polymerized matrix is weakened. Consequently, the decrease in transverse strength in the case of 3PNCEMA is more than $30 \%$, and at the same time, the $\mathrm{P}_{3} \mathrm{~N}_{3}$ ring, which has a small molecular flexibility, further reduces the transverse strength. The fact that the transverse strength of wet specimens is decreased more than that of dry ones, is presumably due to the above-mentioned lack of polymer swelling and to the 6 ester of EMA bonded to the P in the 3PNC-EMA monomer.

Hardness was shown to increase in accordance with the increase in the mixed amount of 3PNC-EMA, but in the case of sample No. 6, it contrarily decreased. As in the case of transverse strength, this was presumably due to insufficient polymer swelling, a large degree of water sorption and the weakness of the bond between the polymer core and the matrix.

The abrasion ratio decreased in accordance with the increase in the mixed amount of 3PNC-EMA. That is, in comparison with PMMA, sample No. 3 proved to have a value smaller than C.5. This can be accounted for by the increase in the compressive strength and hardness due to the bulk-polymerization $^{[10-12]}$ of 3PNC-EMA. That is, abrasion resistance increases almost in proportion to the increase in hardness shown in Fig. 4. This shows that the 3PNC-EMA monomer, which has a cyclic bond, $-\mathrm{P}=\mathrm{N}-$, as well as a hetero bond, produces a very hard polymerized matrix, so that consequently, its abrasion resistance becomes large.

It was thus proved that the monomer composition showing the most preferable physical properties was that in resin sample Nos. 3 and 4. In particular, the dry specimen of No. 4 showed preferable mechanical strength and excellent results in abrasion resistance. The dry and wet specimens with this composition respectively showed values of 1248 and $1040 \mathrm{~kg} / \mathrm{cm}^{2}$ in compressive strength, 2.48 and $2.19 \times 10^{4} \mathrm{~kg} / \mathrm{cm}^{2}$ in elastic modulus and 578 
and $410 \mathrm{~kg} / \mathrm{cm}^{2}$ in transverse strength. The hardness values of this composition, dry and wet, were $\mathrm{HR} 61$ and 53, with a water sorption of $1.85 \mathrm{mg} / \mathrm{cm}^{2}$, and the abrasion ratio of No. 4 was shown to be 0.43 , compared with PMMA regarded as having a value of 1 .

However, in order to increase the transverse strength of the wet samples and to decrease the water sorption, further improvements will be necessary using, as a base, other monomers with PNC-EMA which have hydrophobic groups or other kinds of comonomers.

\section{Conclusions}

The authors examined the basic properties of polymers used with 3PNC-EMA, as components of crown and bridge resin.

The results were as follows:

1) Compressive strength, in both dry and wet samples, showed a tendency to increase in proportion to the mixed amount of 3PNC-EMA.

2) The elastic modulus of dry specimens when compressed increased in accordance with the increase in the mixed amount of 3PNC-EMA, and in the case of wet sample No. 4 , it showed a maximum value of $2.19 \times$ $10^{4} \mathrm{~kg} / \mathrm{cm}^{2}$.

3) Transverse strength in the case of dry sample No. 4 was $578 \mathrm{~kg} / \mathrm{cm}^{2}$, while wet sample No. 2 showed a maximum value of $474 \mathrm{~kg} / \mathrm{cm}^{2}$.

4) Hardness, both in dry and wet samples, showed a tendency to increase in accordance with the increase in the mixed amount of 3PNC-EMA.

5) Water sorption increased in accordance with an increase in the mixed amount of 3PNC-EMA from $14 \%$ to $26 \%$, but thereafter, it did not change even when the mixed amount of 3PNC-EMA was increased.

6) Abrasion resistance was improved in accordance with an increase in the mixed amount of 3PNC-EMA from $14 \%$ to $70 \%$, and at $70 \%$ it showed an optimum value of 0.34 , compared with that of PMMA regarded as 1 .

\section{References}

[1] Nakabayashi, N. and Atsuta, M.: Crown and bridge resins, 5-15, Ishiyaku Publishers, Inc., Tokyo, 1979 (in Japanese)

[2] Suzuki, S.: Preparation of hard crown and bridge resins with new composite fillers, J. Stomatol. Soc., Jpn., 48, 261-276, 1981 (in Japanese)

[3] Atsuta, M.: Thermosetting methacrylic polymers for crown and bridge work, I. Evaluation of 2,2-Di(4-methacryloxyphenyl) propane and glycol dimethacrylate copolymers by the powder-liquid system, $J D A M, 11,214-223,1970$ (in Japanese)

[4] Uchiyama, Y., Atsuta, M. and Nakabayashi, N.: The present time and the future of crown and bridge resins, Dental Outlook, 42, 899-904, 1973 (in Japanese)

[5] Nemoto, K. et al.: Studies on the cross-linked spherical polymer and its microcapsulation for crown bridge resin, $J D M A, 31,165-173,1974$ (in Japanese)

[6] Suzuki, S., Yasuda, N. and AI, M.: Clinical application of new hard resin, The Nihon Dental Review, 504, 47-56, 1984 (in Japanese)

[7] Crown prosthesis of front teeth: The Japanese Society for Dental Materials and Devices, Ed., 45-75, Ishiyaku Publishers, Inc., Tokyo, 1980 (in Japanese)

[8] Dental materials: The Japanese Society for Dental Materials and Devices, Ed., 262-266, Ishiyaku Publishers, Inc., Tokyo, 1982 (in Japanese) 
[9] Hirasawa, T., Hirano, S., Hirabayashi, S. and Harashima, I.: Comparison of physical properties between various crown resins, $D E, 51,12-23,1979$ (in Japanese)

[10] AnzaI, M.: Synthesis of 1,1, 3,3, 5,5-hexa (methacryloylethylenedioxy) cyclotriphosphazene and its properties and use as a composite resin, Dental Outlook, 63, 1115, 1979 (in Japanese)

[11] Anzai, M. and OHAShi, M.: Synthesis of hexa (methacryloylethylenedioxy) cyclotriphosphazene and its properties and use as a composite resin, J. J. Dent. Mat., 3, 401-408, 1984 (in Japanese)

[12] AnZAI, M. and OHAShi, M.: Studies on the reaction product of hexachlorocyclotriphosphazene and 2-hydroxyethyl methacrylate and on the physical properties of its polymer, J. Nihon Univ. Sch. Dent., 26, 109-118, 1984

[13] AnZai, M. and OHıSHI, M.: Studies on composite resins with hexa (methacryloylethylenedioxy) cyclotriphosphazene used as a monomer, J. Nihon Univ. Sch. Dent., 26, 238-242, 1984

[14] Suzuki, K., Horie, K., Masuda, K. and Suzuki, S.: Studies on crown and bridge resin (Part 2) - On the physical properties of crown and bridge resin with PMMA-1, 5-dimethacryloxy naphthalene-triethylene glycol dimethacrylate-, JDMA., 33, 344-349, 1976 (in Japanese) 